\title{
Correction to: Difficult Conditions in Laparoscopic Urologic Surgery
}

\author{
Sachinder Singh Hans
}

\section{Correction to:}

S. S. Hans (ed.), Extracranial Carotid and Vertebral Artery Disease, https://doi.org/10.1007/978-3-319-91533-3

Late corrections to chapters 3 and 10 have been corrected as listed below:

1. Chapter 3: Page 22, the last sentence in paragraph "Occlusive lesions of the....." has been updated as below:

"For example, the costocervical and thyrocervical branches of the Subclavian Artery can develop collateral circulation between the external carotid and subclavian arteries."

2. Chapter 10: Page 146, reference 14 has been updated as below:

"Calligaro KD, Dougherty MJ. Correlation of carotid artery stump pressure and neurological changes during 474 carotid endarterectomies performed in awake patients. J Vasc Surg. 2005;42:684-9."

The updated online version of these chapters can be found at https://doi.org/10.1007/978-3-319-91533-3_3

https://doi.org/10.1007/978-3-319-91533-3_10 